\title{
South African Khoisan Literature in the Context of World Literary Discourse
}

\author{
By Lesibana Rafapa*
}

I demonstrate how South African Khoisan literature enriches literary discourse in the global context, using the criteria of strangeness, cross-cultural dialogue and social cohesion. I consider the spatial-cultural inflections of Khoisan literary art from the theoretical perspective of Maurice Halbwachs's 1950 concept of space and collective memory. I compare Khoisan and Northern Sotho folktales within the global and Southern African contexts. I intend to foreground how distinctively Khoisan discourses on postcolonial experiences find literary expression, adopting Tomaselli and Muller's (1992:478) observation that "cultures are distinguished in terms of differing responses to the same social, material and environmental conditions." I argue that intercultural dialogue that an appreciation of strangeness may unlock, promotes social cohesion that would otherwise not be achieved.

Keywords: Collective memory, Cross-cultural dialogue, Khoisan literature, Northern Sotho folktales, Strangeness.

\section{Introduction}

The main focus of my essay is an analysis of some San and Northern Sotho folktales with the Lion, Jackal, Hyena, Baboon and Tortoise as characters. The words San and Bushman refer to the same indigenous people found today mostly in southern Africa. The |Xam are one among the many San groups. A distinction is made between the Khoi and San, with the Khoi also consisting of many small groups. Writers such as Andrew Bank prefer to refer collectively to the Khoi and San as Khoisan groups, as seen in his remark that "the |Xam narratives are very squarely in keeping with the folktales of other Khoisan groups" (Bank 2006: 193).

I select the San folktales from what is known in South African Khoisan scholarship as the Bleek-Lloyd archive of the folklore of the |Xam San of the Northern Cape collected in Cape Town in the 1870s (McGranaghan 2014: 671, Wessels 2008: 299, Bennun 2004: 8, Theal 1911: xxxiii), and published exhaustively for the first time in London in 1911. While, as Bank (2006: 193) remarks, the Khoisan folktales "display a striking unity across the three central themes: narratives of creation, narratives about the people of the Early Race, and tales of the trickster", I compare only the trickster folktales of |Xam and Northern Sotho literatures of southern Africa. I analyse some Northern Sotho folktales from a 1994 and a 2015 collection.

As I indicate elsewhere in this article, for the Northern Sotho cultural group the narratives of creation and of the people of the Early Race exist mostly

\footnotetext{
* Professor, Department of English Studies, University of South Africa, South Africa.
} 
tangentially, embedded in tales of the trickster. This has led to scholars of the Northern Sotho folktale such as Phaka Makgamatha (1993: 69) plausibly arguing that, on the whole, Northern Sotho folktales are trickster narratives in which "small and weak animals" play the role of tricksters while "their dupes are almost invariably bigger and stronger animals". I interrogate the reason for similar characterization being present in other world literatures, like those of the West, through my refinement of the definition of the Khoisan theory-from-below.

By theories from below, I mean epistemological ontologies of the indigenous peoples of the world, seen by the Khoisan researcher DyllMyklebust (2014: 525) as privileging "the ordinary person as a theorist involved in developing ideas to guide an understanding of his/her personal/ collective/historical and social worlds". It is such theories from below which, in Halbwachs's notion of the collective memory, tie spatial-cultural groups to the "spatial image" that as a result of perceived stability "gives us an illusion of not having changed through time and of retrieving the past in the present". I apply to my examination of the Khoisan and Northern Sotho folklores Tomaselli and Muller's (1992: 478) idea that "cultures are distinguished in terms of differing responses to the same social, material and environmental conditions". In this way, I hope to establish the extent to which some physical spatial elements, like the weaker trickster animals in folktales across cultures of the world, merely represent what Halbwach (1992: 2) describes as the cultural group's spatial yielding and adaptation "to its physical surroundings", following its transforming "the space into which [it] has been inserted".

The differing collective memories and cultural responses to the environment among the various Khoisan groups, have led a number of writers to sketch both differences and similarities in the folktales these groups have produced. On the one hand, writers such as Wessels (2008: 229) have identified aspects in |Xam folktales, of a distinctively |Xam hunter-gatherer theoretical content. On the other hand, compelling demonstrations have been published in later studies of Khoisan folklore by writers such as DyllMyklebust (2014: 525), of connective theoretical threads characterising |Xam, other San and even Khoi folktales covering diverse southern African geographical areas. According to Bleek and Lloyd (1911: xxix), when whites formed their first settlements in the region in the $17^{\text {th }}$ century, "a vast region inland from the Kathlamba mountains nearly to the Atlantic shore was inhabited exclusively by Bushmen" and in present day terms this covers the whole of the Cape, the whole of Lesotho, the whole of the Free State, the whole of Botswana, the Northern Cape, the Kalahari and Namibia. The Northern Cape |Xam and other San communities thus belong to what may be regarded as one big San nation scattered by historical and economic factors.

Within the South African socio-political space, the word San is now preferred in referring to Bushmen. The word is derived from the term Saan of the language of the Khoisan group called Khoekhoegowab, meaning "people who gather wild food". ${ }^{1}$ This should not be misunderstood to mean that the San identify themselves by means of this collective appellation. One should always

\footnotetext{
${ }^{1}$ See: http://www.sasi.org.za. [Accessed: 20 April 2016]
} 
bear in mind that the San identify themselves by referring to their many different groups, such as the |Xam. They have no collective name for themselves. ${ }^{1}$ Historically, the San also came to be known as Bushmen or Bosjesman, after European colonists called them by this and other names that now seem to have fallen out of use, such as Soaqua. ${ }^{2}$ The San are said to have been proud of the name Bushman, as they associated it with their heroic resistance to colonisation. ${ }^{3}$ All the same, the word Bushman is "now abandoned as it is [considered] derogatory". ${ }^{4}$

Accounts like those of Bleek (Bank 2006: 192), of the sphere of influence of the mythology of the |Xam on folktale narrative style, seek to exclude narrative textures of other southern African indigenous peoples beyond the Khoisan, such as the Sotho. Khoisan is a term that collectively describing the distinct Khoi and San groups, with the Khoi or Hottentots characterized by an agrarian lifestyle while the San existed as hunter-gatherers (Bleek and Lloyd 1911: xxvii, xxxii, Wittenberg 2014: 599). ${ }^{5}$ The word Hottentot, like Bushman, is no longer acceptable within the South African democratic context. Unlike the scholars of Khoisan indigenous literature, I argue that Northern Sotho lore recreated constructively from Northern Sotho folktales, demonstrates oneness with |Xam mythology. I show below that the exaggerated difference between the |Xam and Northern Sotho indigenous literatures, for example, is actually only with regard to the style of representation of the creation and First Race aspects of a common folkloric theory.

Although I highlight a common theory-from-below between |Xam and Northern Sotho folktales differing only in the manner of narrative presentation in the geographically separate spatial-cultural peoples, I observe the primacy of avoiding a kind of totalization that some comparisons of the subgroups of Khoisan literature have fallen into. I argue that Northern Sotho and |Xam literatures differ in aspects other than their common theoretical underpinnings. I emphasize that such differences of narrative texture do not negate the existence of a common theory at the underlying level. For me the surface level differences between |Xam and Northern Sotho folktales that I compare, is due to what Halbwachs would refer to as "spatial image alone" of a basically common permanent part of collective memory. According to Halbwachs (1992: 15), the "spatial image" component of collective memory "by reason of its stability, gives us an illusion of not having changed through time", and "of retrieving the past in the present" as if it were the truly permanent theory part of collective memory.

I argue that such an acknowledgement of realistically changing spatial aspects of the collective memory of the Northern Sotho indigenous group, helps to avoid the trap of what writers such as Solomon (2009: 36) censure as "anthropological readings" of folktales. Solomon (2009: 36) helpfully chafes

\footnotetext{
${ }^{1}$ See: http://www.siyabona.com. [Accessed: 20 April 2016]

${ }^{2}$ See: http://www.sahistory.org.za, http://www.sasi.org.za. [Accessed: 20 April 2016]

${ }^{3}$ See: http://www.saisi.org.za.

${ }^{4}$ See: http://www.encounter.co.za, http://www.siyabona.com. [Accessed: 20 April 2016]

${ }^{5}$ See also: http://www.encounter.co.za. [Accessed: 20 April 2016]
} 
against determinist readings that strive to identify the presence of what some analysts describe as cross-Khoisan theories-from-below in |Xam narratives, without conceding to the presence of endemically |Xam features. Solomon (2009: 36) explains that Northern Cape |Xam, on the one hand, responds spatially to basically Victorian colonization while on the other, the Kalahari San folktales set in a different historical era respond spatially to mostly twenty first century colonial conditions. For this reason, what in Halbwachs's (1992: 15) terms may be described as varying spatial images of the |Xam and Kalahari San, have resulted in the respective indigenous literatures bearing some distinct narrative characteristics. This is the case despite the presence of constructively generic features of the folktale in the two indigenous literatures which, one may argue, go even beyond the Khoisan demarcation to encompass Western and other spatial-cultural inflections of the folktale genre.

The manner in which |Xam literature is credited with a worthy contribution to world literature, as I argue, should be within the context of its collective impact with regional indigenous literatures of the Khoisan, Sotho and Nguni. Bleek argues for a supremacy of San mythology (Wessels 2012: 36) that stems from the Nguni and Sotho-speaking African people's intellectual incapacity for "further development if left on their own". I see Bleek's position more as betrayal of colonial silencing of the Nguni and Sotho-speaking people of South Africa perhaps to justify their colonial conquest and appropriation of their territory, rather than as a genuine demonstration that they do not possess a commonly profound permanent theoretical aspect of collective memory. Wessels's (2012: 36) observation that the Nguni and Sotho-speaking people of South Africa "presented the biggest obstacle" in the nineteenth century to European hegemony in southern Africa" is for me an index of a theoretical depth of this group of native southern Africans equaling that of the |Xam that he was singling out.

I argue in this article that it is from such a broader coalescence with South African indigenous literatures and the folktales of the literatures in other parts of the world that |Xam narratives impact world literature positively. I interpret data collected from the selected |Xam and Northern Sotho narratives in order to determine the position of South African Khoisan literature on the scale of what Mapadimeng (2013: 71) sees as the function of the arts, including literature, in the context of post-apartheid South Africa, being "well placed to promote intercultural dialogue". One social function of such intercultural dialogue is much needed social cohesion, considering ideological fractures after more than 400 years of colonial intrusion, including the way unity among the indigenous South Africans was harmed. On the front of southern African literary studies, social cohesion was potentially harmed in the divisiveness of skewed studies of indigenous folkloric mythology as exemplified in Bleek's scrutiny of $\mid$ Xam folktales, unjustifiably constraining the influence of what he and some of his contemporaries saw as an isolated |Xam literary tradition - as far as the permanent theory part of collective memory is concerned.

Despite the need to discern an overlapping theory part of collective memory within the southern African context, any oversimplification of 
harmony beyond such a permanent aspect of collective memory between the Xam and other indigenous groups in the region, would detract from a more dynamic intellectual response to colonization as reflected in |Xam folktales. Studies of Khoisan literature have always been intertwined with intricate questions of power relations, as groups such as the |Xam came into contact with neighbouring population groups. In as much as I demonstrate in this article that the literary cultural connection of the |Xam with the other indigenous groups exists, such convergences should not simplistically be equated to harmony or conflict that coincides with cultural affinity. As far as the sometimes overemphasized friction between the |Xam and white colonizers is concerned, Deacon (Solomon 2009: 31) accurately points to nuances that accompanied such social interactions in his remark that,

Undoubtedly it was the colonial presence that tragically sealed the fate of the /Xam, and it remains an essential frame for understanding, but it is sometimes used as something of a blunt instrument. Nor were the /Xam unaccustomed to "other people". The /Xam shared their landscape with the warlike Korana (!Ora), the antagonists in several narratives. They, rather than the Boers, were the /Xam's traditional enemy. The /Xam had also been in contact with their Bantu-speaking neighbours since at least 1805 .

Although several |Xam texts describe colonial cruelties, literary evidence in Khoisan literature exists that European colonists were "not necessarily the most feared or disliked of the |Xam's neighbours, though they proved the most powerful" (Solomon 2009: 31). One example that the notions of enemy or foe in Xam folktales is not simplistically white colonizer versus black indigenous inhabitant, is the folktale of "a /Xam man injured by a 'Kafir' who had stolen his mother's spoons" (Solomon 2009: 31). A writer such as Theal (Bleek and Lloyd 1911: xxxi) gives a historical account that "Bantu" neighbours of the Xam regarded the San "as beings without a right to the soil over which they roamed, as untamable robbers whom it was not only their interest but their duty to destroy". With such a lack of intra-racial social cohesion, the spatial image of the |Xam represented in the collective memory of the folktale above, enhances the contribution of |Xam literature to a non-racial world literary discourse. In postmodernist views of the subject as ever shifting phenomenologically in tune with environmental dictates of meaning, this kind of anti-racist discourse in |Xam folktales deserves recognition. Such recognition can be facilitated from the perspective of Castle's (2007: 3) postmodernist notion of the function of literary theory, to help critics "understand both the particular contexts and the ideological points of view that help shape literary texts". The |Xam literary texts are best understood within a thorough understanding of the southern African colonial context of the eighteenth century and the non-racial spatial image of |Xam collective memory.

Within the Khoisan mythological tradition of symbolically embracing good human and animal persons while rejecting bad ones, the value of social cohesion achieved by such an ethical aspect, should enrich the spatial aspects 
of collective memory to transcend racial discrimination. With literary portrayals of simplistic racial friction threatening global social cohesion today, the elimination of racism in |Xam folktales deriving from a nuanced collective memory of regional and world space, proves a worthy contribution to world literary discourse.

\section{Other Animal Persons than Mantis, Hartebeest and Eland in Khoisan Indigenous Literature}

Although some |Xam tales have at their centre the mutable Mantis or /Kaggen interpreted differently by critics of Khoisan literature as a trickster or a god of creation, and incarnating alternately as the Eland or Hartebeest (Bleek and Lloyd 1911: 3-17), for comparative purposes with Northern Sotho indigenous literature, I exclude them. This is because, as I argue, the Northern Sotho folktales only refer to the myth of the Mantis or /Kaggen implicitly in folktales with animal and human persons possessing speech alike and changing form to trick other characters, as I indicate with the character of the ogre elsewhere.

Bleek and Lloyd (1911: 3-17) give an account of the myth of the Mantis in the |Xam folktale entitled "The mantis in the form of a Hartebeest". Sisters sent by the father from a hunter-gatherer |Xam family to collect a sort of cucumber called gambroo get cheated by a Mantis resembling a dead hartebeest. They use stone knives to cut the hartebeest to pieces, but the chunks of meat drop themselves on soft parts of the bush to avoid discomfort, and even talk to one of the sisters, after which they jump back together and chase the sisters back home, this time assuming the form of a human being. As the children near their home, the Mantis-turned-man runs away displaying the soles of his shoes, and then jumps into a river before rising again in the form of a Mantis. As the sisters tell their ordeal to their father, the father explains to them that they "Have been and cut up the old man, the Mantis, while he lay pretending to be dead" in front of them (Bleek and Lloyd 1911:13). The fatigue the sisters have felt while the Mantis chased them home, leads them to declare that they will no longer ever go hunting again, but "shall altogether remain at home" (Bleek and Lloyd 1911: 17). This explains why to this day, girls in |Xam communities do not have the social role of hunting.

I discuss here only the |Xam fables having the Lion, Hyena, Tortoise/Turtle, Baboon and Jackal as characters. This is because the concrete characters of the Northern Sotho folktales that I compare with |Xam narratives, exclude the Mantis or /Kaggen, while they do share with the |Xam folktales the animal persons I mention above. My exclusion of the Mantis in my comparison of the two categories of folktales is in keeping with the argument of my article that the Mantis for the Northern Sotho speaking black people of South Africa exists only at the abstract level as part of a narrative theory these indigenous people share with the Khoisan, ignored so far by critics of Khoisan literature. 
My recognition of indigenous peoples as theorists, is in the sense of what the Khoisan researcher Dyll-Myklebust (2014: 525) defines as pillars of critical indigenous qualitative research. According to him, this kind of research "recognises that information is theoretically incomplete and always open to potential change; and ... privileges the ordinary person as a theorist involved in developing ideas to guide an understanding of his/her personal/collective/ historical and social worlds" (Dyll-Myklebust 2014: 525).

One |Xam story I find significant is "The Hyena's Revenge" (Bleek and Lloyd 1911: 125). As a bad animal person with negative attributes contrasting him in present oral storytelling times with human animals known for their proper manners, the Hyena typically deceives the Lion to visit the former's house. After a prank regarding his spirit of sharing exemplified when he pours soup into his child and wife's mouths, the Hyena kills the Lion by pouring boiling soup into the Lion's mouth, even covering the dying Lion with the hot pot and finishing him off with a stick. Bennun (2004: 15) clarifies the beastly qualities apportioned the Lion by the San deriving from the Early Race period: "he catches people at night because he feels he is a lion's man ... he has hair, he is a lion, his hands are a man's ... He shines with his eyes, which are like fire. And he smells with his nose".

In |Xam theory, folktales at present are conceived and narrated against the backdrop of a notional First Times or Early Race period, sometimes called the days of the First at Sitting People by scholars of Khoisan literature, including Bennun (2004: 17), Hollmann (2004: 7, 370) and Wessels (2012: 37). According to Khoisan mythology, all animals were once people with acceptable human conduct (McGranaghan 2014: 676, Hollmann 2004: 7, Bleek and Lloyd 1911: 126-127). This was the case until their fall from grace as when Baboons once engaged in anti-social behaviour, or when the Lion once killed and ate people for the first time, or when the Hyena stopped being generous and started greedily eating chunks of fat meat without sharing it with others. In later times "The most typical exemplars of persons who did not act in accordance with the norms and aims of |Xam society were to be found (unsurprisingly) in non-human communities" (McGranaghan 2014: 674). After the First Times, the| Xam thus have human persons with good conduct and animal persons with bad behaviour in their notional space.

The 1875 |Xam storyteller Díä!kwain typically ascribes the Lion's credulity with foolishness, in spite of being expected within indigenous Khoisan literary theory to always gain the upper hand for the reason that "he is a Lion who kills people; he also eats people" (Bleek and Lloyd 1911: 126-127). The ridiculous foolishness of the Lion in misclassifying the Hyena in the category of generous persons, intensifies when one remembers, as McGranaghan (2014: 676) observes, that among the |Xam "human hunters who ate up springbok without sharing ... were described as 'hyenas', a powerful statement of the inappropriate nature of their actions".

Within Xam cosmology, both lions and hyenas are "people that are different"; and, moreover, they are "things which are angry" because they kill and eat people (Hollmann 2004: 33). As the hyena is smaller and weaker than 
the Lion, in typical Khoisan folkloric fashion, sympathy in "The Hyena's Revenge" hermeneutically goes to the Hyena, especially as in another Khoisan tale the Lion was the first to deceive the Hyena. Bennun (2004: 15) clarifies the beastly qualities apportioned the Lion by the San deriving from the Early Race period: "he catches people at night because he feels he is a lion's man ... he has hair, he is a lion, his hands are a man's ... . He shines with his eyes, which are like fire. And he smells with his nose."

Baboons' fall from grace during the Early Race, occurred when they killed and ate an Early Race woman who lived with them out of greed, because she was too fat to be resisted; and when they violated meat-sharing practices by offering human flesh to human persons, and lying that it was gemsbok meat, after which the First Bushman people cast a curse on Baboons (Hollman 2004: 7). In punishment for "this gruesome insult", the people caught a Baboon and pressed his buttocks onto red-hot stones, with the fire burning off all the baboon's buttock hair and shrivelling its tail to the shape known today. As a result he developed a phobia for meat "because he remembers that the fire once burnt off for him his tail tip", a fire for cooking meat (Hollman 2004: 7). With these mythical incidents at the back of the mind, baboons in Xam culture are associated with all imaginable shame and danger and are to be avoided at all cost.

One tale related in 1878 by the |Xam prisoner called |Han $\ddagger$ kass'õ, is about a troop of feeding Baboons who kill Mantis's son and play ball with his eye, after the son has mistakenly revealed to the Baboons that his father |Kaggen had sent him to fetch sticks, so that "his father might take aim at the people who sit upon heels" (Bleek and Lloyd 1911: 16-37). The writers (Bleek and Lloyd 1911:33) significantly point out that one moral of pain suffered by Mantis's son was for the Xam not to associate with strangers or "people who are different" without caution, as a safety measure.

Not all animal characters in |Xam folktales fall neatly within classification as either attractive or repulsive. Within such an ontology as a pan-Khoisan cultural survival kit during often violent $19^{\text {th }}$ century British colonisation and subsequent apartheid oppression, the Jackal is alternately "an attractive roguish figure who is able to outwit the powerful - in particular, predators such as lions" as well as a repulsive figure "associated with negative connotations such as cunning, cowardice and selfishness" (Wittenberg 2014: 593, 599).

The Jackal and Tortoise are more trickster animals within Khoisan indigenous literature defeating the more feared and yet gullible Hyena and Honey Badger. The San storytellers Díä!kwain and Kabbo in 1875 dictated to Lloyd the tale of a Hyena who had caught a Quagga (Bank 2006: 240). The cleverer Jackal feigns love for the Hyena and advises the latter to go and fetch his wife and children. After the Jackal and his wife have climbed up a tall house of sticks and made a fire inside it, they cook the Quagga in a pot. Upon the Hyena's return, the Jackal tells him to leave his wife and children below and pull himself up with a rope made of the entrails of a mouse. Just as the Hyena gets a glimpse of the stew in a pot perched on top, the Jackal cuts the rope. The Hyena nearly falls into the fire below. After persuasion by the Jackal, 
the Hyena makes a second attempt, after which the Jackal's wife this time cuts the rope. "Now the Hyena does land in the fire, burning the back of his legs and his hindquarters, with lasting consequences for his appearance" to this day (Bank 2006: 240).

Another tale by Díä!kwain archived on 24 February 1875 (Bank 2006: 240-241) concerns the Water Turtle pretending to be ill and luring the Honey Badger to heal him by stroking the back of his neck with his hand. As the foolishly sympathetic Honey Badger touches the Water Turtle's neck, the latter "pulls its head back into the shell, trapping the Ratel's [Honey Badger's] hand". The coaxing continues successfully until the other hand is also trapped, then the Honey Badger's rear foot, followed finally by his front foot. Realizing that he has been deceived only after he is completely trapped, the Honey Badger tries in a rage to crack the tortoise's shell, without success. "In the meantime his hands decay", explaining the Honey Badger's "small stunted feet and lengthy claws" (Bank 2006: 241).

Resonances with latter day Khoisan anticolonial discourse, of the weaker animal persons outwitting the stronger ones whose ignoble behaviour is described in an exaggerated manner, are remarkable. The views of writers such as Wittenberg (2014: 599) support this function of Khoisan literature, in his remark that Khoisan oral literature incorporates encounters with colonisers and oppressors in which the Khoisan are symbolised by trickster and other weaker animal persons who invariably outwit the stronger coloniser represented by animals of prey such as the Lion. I now turn to southern African regional folktales outside the Khoisan sphere yet deploying the characters of the Lion, Hyena, Tortoise, Baboon and Jackal in ways which show an outlook and mythology common in a broad sense with those of the Khoisan.

My position is that even if narrative-theoretical coincidences are found between Khoisan and Northern Sotho indigenous literatures, allowance should be made for idiosyncratic features in each of the constitutive literatures. This is as true for Khoisan and Northern Sotho as it is for the other regional indigenous literatures. Wittenberg (2014: 599) is referring to, in his cautions that "assumptions of an undifferentiated commonality across diverse southern African Khoi and Bushman societies are ... problematic, given pronounced divergences in economic mode, where Bushmen or San are generally associated with a hunter-gatherer lifestyle and the Khoi practised a pastoral subsistence".

\section{The Animal Persons of Lion, Hyena, Tortoise, Baboon and Jackal in Northern Sotho Indigenous Literature}

In a Northern Sotho folktale, the Hyena asks the Jackal to look after his six children when the latter goes hunting (Phokwane 2015: 239-240). While the Hyena is away hunting, the Jackal eats one of the Hyena's children. Upon the Hyena's return, the Jackal brings the first child twice to suckle in order to reach the count of six and fool the Hyena. The challenge comes on the fifth day when 
only one child is left. The Jackal eats the last child and smears his mouth with blood. At the usual breastfeeding time, the Jackal lies to the Hyena that during the day Baboons took away all the children and ate them and assaulted him brutally when he tried to resist. The Jackal then points to the direction the Baboons supposedly took, and the two animals go off to search for the Baboons.

On their way they find a huge rock. Cunningly the Jackal warns the Hyena to hold fast to the rock while the former climbs up to look for the Baboons, lest the rock falls. Once at the top, the Jackal escapes from behind. When the Baboons arrive, they react in typical behaviour within what researchers so far understand as specifically Khoisan folkloric episteme, namely that Baboons are not like other animals because "they ... resemble people" in wisdom (Hollmann 2004: 10). The Baboons tell the Hyena that the Jackal has tricked him, as the rock is firm. The Baboons even climb and gambol on top of the rock to demonstrate this. Furious, the Hyena gets off to look for the Jackal. To this day the Jackal runs away from the Hyena.

In parallel manner, the despicable Tortoise in the Northern Sotho folktale "Makopo a boTšhwene" victoriously tricks the "cleverer" Baboon (Makopo 1994: 60-61). The collector introduces the narrative in typical Northern Sotho folkloric fashion, where the setting is described as "bogologolo (meaning during the earlier age)", when "maswika a sa le boleta tšhwene e se na makopo (when rocks were still clammy and the Baboon was without his steep forehead)". In a research essay forming the Introduction to the collection, the compiler explains that all Northern Sotho folktales bear an opening which includes the word kgale/kgalekgalelbogologolo, meaning "during the earlier age" (Makopo 1994: 2).

I argue that such a Northern Sotho formulaic setting, points to the Khoisan theoretical notion of the First Time. When the Baboon chances upon a Tortoise, the former mocks the latter on account of his shell. When the Tortoise admonishes the Baboon for lacking respect, the latter challenges the former to a race as proof that the Tortoise deserves respect. After agreeing, the Tortoise cleverly begs members of his family to line the path of the race. On the great day, the sweating Baboon at every turn finds Tortoises that utter identical remarks of self-praise taught to them by the contending Tortoise. At the winning post, the Baboon finds a relaxed and gloating Tortoise "a letile mme a hwile ka disego (waiting in great amusement)". When the Baboon looks down in shame to avoid eye contact with the Tortoise, his forehead grows to better conceal his face. Since that day the Baboon uses his steep forehead to avoid eye contact with all animal and human persons "ka baka la dihlong (out of shame)" (Makopo 1994: 61).

In "Tau le Mmutla (The Lion and the Hare)", an extremely hungry Lion stumbles upon a reposing Hare (Makopo 1994: 30-33). The Lion explains that he is so hungry that he will have to eat the Hare. The Hare pleads leanness and the fact that he is too tiny to satisfy the Lion's hunger. Supposedly in compensation, the Hare comes up with a trick that will bring the Lion plenty of meat. After agreement, the Lion buries himself, exposing only his teeth. 
Boasting that he had killed and deposed the Lion, the Hare invites all animals to come for a victory dance over the carcass of the Lion. When it is the turn of the Buffalo to gallop over the Lion's mouth, the Lion jumps up and kills the Buffalo. Thereafter the Lion praises the Hare, calling him "Motho yo bohlale (a clever person)" (Makopo 1994: 31). Such a reference to the Hare as a person smacks of the Khoisan cosmology in which animals have all once been people and continue even after the Early Race to be persons, the meaning embedded in the appellation "animal person".

Hereafter the Hare convinces the Lion that a tall thatch should be erected on which to hide leftover meat. But after the Hare has tricked the Lion to climb to the top of the structure, the Hare clutches the Lion's tail, exclaiming ironically that there are so many Ticks stinging the Lion, as if in his wiliness the Hare is not behaving as ignobly as the lowly Tick within the hierarchy of persons post the Early Race. After the Lion has permitted the Hare to remove the Ticks, the Hare sticks thorns into the tail, fixing the tail to the roof. The Hare then goes to the boiling pot and lifts a fat piece of Buffalo meat, asking "Rakgolo, na ke je ye? (Grandpa, can I eat this one?)". When the expectedly greedy Lion objects, the Hare then lifts up a lean peace, upon which the Lion assents. The Hare instead drops the lean piece of meat and lifts another fat piece. The furious Lion attempts to descend from the thatch but fails as his tail is stuck. Hereafter the Hare and other animal persons feast on the meat with the Lion watching helplessly. After the rest of the animal persons are gone, the Hare kills the Lion and sings vainly, wearing the Lion's hide as a trophy.

In these Northern Sotho folktales the mightier and stronger Hyena, Baboon and Lion are tricked by the weaker Jackal, Tortoise and Hare. There are clear thematic parallels in such a discursive configuration with notions of weak and strong displayed by the Khoisan folktales I have considered in this article. The trickster and duped animals keep reminding the reader of some Khoisan collective memory concept of unacceptable conduct of greed pigeon-holing some creatures as Khoisan animal persons. We see this concept resurfacing when the Lion in the Northern Sotho folktale allows the Hare to eat only lean pieces of meat, so that all the fat pieces can be eaten by the stereotypically rapacious Lion alone without sharing with anyone.

The Mantis in Northern Sotho folktales assumes the form of a faked human person whose concealed unacceptable behaviour akin to that of predators comes to light only as the plot of the folktale unfolds. Such a cannibalistic figure in Northern Sotho indigenous trickster tales is called a lekgema or ogre. An example is the Northern Sotho folktale entitled "Mokgadi le ledimo lejabatho". It recounts the saga of the newly wed Mokgadi.

When during the first journey together after marriage the thorns hurt Mokgadi's feet, the new husband licks blood from the bride's wounds (Makopo 1994: 25). The character of the ogre in this Northern Sotho folktale reveals that in the world view of Northern Sotho folktales, the notion of the Early Race, the First Times or the days of the First at Sitting People (Bennun 2004: 17, Hollmann 2004: 7, 370, Wessels 2012: 37) continues to linger at the underlying level of narrators' and audiences' consciousness. The scholar of 
Khoisan literature Neil Bennun explains the conduct of the First at Sitting People when "the very notions of animal and human had never meant a thing" and "the behaviour expected of the beasts of prey, the scavengers, the herbivores and the insects was negotiable [where] the Ticks were generally agreed to be very aggressive people ... the Quagga were family orientated and the Lions ... sometimes supernaturally aggressive and at other times foolish in the extreme, were by and large to be avoided at all costs" (Bennun 2004: 17).

The First at Sitting People "often ate each other" and "fed their families on their own innards and they did not feel bound to keep their own shapes" (Bennun 2004: 17) - as the ogre walking with Mokgadi in the Northern Sotho folktale is poised to do. However, in the context of the post-First Times Khoisan narratives and present day Northern Sotho indigenous tales, it is taboo for human animals to consume human flesh. In this way, Mokgadi tricks the ogre by lying that she is returning to fetch her exquisite gourd that she had forgotten at home (Makopo 1994: 25). Upon awareness of the cannibalistic licking of human blood of the ogre, Mokgadi's parents exclaim "Monna yola e swanetše ya be e le lekgema! O dirile gabotse wa tšhaba. $\mathrm{O}$ be a tla re go fihla mo a yago, a go bolaya, a go ja. (That groom must be an ogre! You did well to escape. Otherwise he was going to kill and eat you as soon as he arrived where he was headed to.)" (my own translation) (Makopo 1994: 26).

Differently from the Khoisan narrators, the Northern Sotho and possibly other Sotho peoples do not distil the myth of the Early Race to tell it separately alongside their etiological and other folktales. They take for granted that this is shared knowledge between the narrator and audience. For this reason, within Northern Sotho and other regional indigenous literature, one does not come across an oral tale or kum such as this one existing in the corpus of Khoisan orature:

The First at Sitting People were those who first inhabited the earth. It was their children who worked with the Sun. This is why the people who inhabited the country after them say that those children made the sun ascend, feeling that their mothers had agreed together that they should throw the Sun up for them ... . When the First at Sitting People had passed away the Flat Bushmen inhabited their ground. That is why the Flat Bushmen taught their children the stories of the First at Sitting People. The Sun had been a man. He talked. They all talked: the other one too, the Moon. While they spoke, they used to live on the earth. They do not talk, now that they live in the sky ... The beasts of prey were once people. They became beasts of prey because of the Lynx and the Anteater - they were the ones responsible. They cursed each other because of the little Springbok's doings. They cursed each other. All things were once people ... The carrion creatures, the reptiles, the huge mammals, the primates, the antelope herds, the parasitic insects, the beasts of prey, the rodents and the birds were all men and women in the time of the !Khwe / /na s'o!kwe the First at Sitting People.

(Bennun 2004: 11-15) 
With such a common theoretical thread linking the Khoisan and Northern Sotho indigenous literatures, at the deeper, constant collective memory level the two building blocks cannot be different in the sense of Tomaselli and Muller's (1992: 478) observation that "cultures are distinguished in terms of differing responses to the same social, material and environmental conditions". It is only the fact of the Khoisan and Northern Sotho being historically distributed over divergent geographical areas that may distinguish their respective spatial images as reflected on the surface level of their respective corpuses of folktales. This is because the spatial image aspect of a cultural group's collective memory only gives the impression of permanence while it is in reality mutably adaptable to the physical environment.

\section{Conclusion}

Apart from the influence of Khoisan folkloric theory impacting at the abstract level on regional literatures such as the Northern Sotho folktales, it has to be credited with articulating in its folktales a theory apparently informing the collective memory reflected in folktales of other distant cultures such as the Western. In the Cinderella fairytale, for example, the attribute of human speech goes beyond human animals and beyond animate creatures. This feature of Western folktales in a sense goes back to the Early Age when even the sun and moon were human animals. Such a widening of the psychic rationalization of the behaviour of some characters even in Western and folktales of other cultural groups, could transcend a compartmentalization often discernible when folktales from different regions of the world are analysed. This kind of analytical approach can only contribute positively to the improvement of global social cohesion in world literary discourse hitherto tending to emphasise superficial differences tied to varying spatial images, forming parts of the collective consciousnesses that folktales across the world reflect.

The antisocial nature of Khoisan folktales demonstrated earlier, is also bound to mellow global social cohesion by means of a literary discourse blurring racial differences. While different races constituting the world population are not to be rejected in the spirit of celebrating difference, to use Njabulo Ndebele's words (Mapadimeng 2013: 73), Khoisan folkloric theory found also in Northern Sotho folktales and probably also in other world regional folktales can be identified only if we embrace the necessity to "engage with strangeness" in order to ascribe it to the spatial image in collective consciousness. In this way "strangeness" thus problematized becomes "meaningful and sustainable" in the realization that it facilitates global social cohesion rather than hinders it by ignoring underlying collective memory commonalities. 


\section{References}

Bank, A. (2006). Bushmen in a Victorian world. The remarkable story of the BleekLloyd Collection of Bushman folklore. Cape Town: Double Storey Books.

Bennun, N. (2004). The Broken String. The Last Words of an Extinct People. London: Penguin Books.

Bleek, W.H.I., Lloyd, L.C. (1911). Specimens of Bushman Folklore. London: George Allen \& Company.

Castle, G. (2007). The Blackwell Guide to Literary Theory. Malden: Blackwell Publishing.

Halbwachs, M. [1950]1992. On Collective Memory. Coser, Lewis A. (Trans. \& Ed.). Chicago, London: University of Chicago Press.

Dyll-Myklebust, L. (2014). Development narratives: the value of multiple voices and ontologies in Kalahari research. Critical Arts 28(3): 521-538.

Hollmann, J.C. (2004). Customs and Beliefs of the |Xam Bushmen. Johannesburg: Wits University Press.

Makgamatha, P.M. (1993). The trickster tale and its cultural symbolism in Northern Sotho. South African Journal of Folklore Studies (4): 60-69.

Makopo, S.A. (1994). Moepathutse. Dinonwane. Pretoria: Actua Press.

McGranaghan, M. (2014). "Different people" coming together: representations of alterity in |Xam Bushman (San) narrative. Critical Arts 28(4): 670-688.

Mapadimeng, M.S. (2013). The Arts and Interracial Dialogue in Post-apartheid South Africa: Towards Non-racialism? In: Ebewo, P., Stevens, I. and Mzo Sirayi (eds.) Africa and Beyond: Arts and Sustainable Development, 69-81. Newcastle upon Tyne: Cambridge Scholars Publishing.

Phokwane, P.P. (2015). Phukubje le Phiri. In: Mamabolo, M. (eds.) Khupamarama, 239-240. Pietermaritzburg: Shuter and Shooter.

Solomon, A. (2009). Broken strings: interdisciplinarity and /Xam oral literature. Critical Arts 23(1): 26-41.

Theal, G. McCall. (1991). Introduction. Specimens of Bushman Folklore, xxv-x1. London: George Allen \& Company.

Tomaselli, K.G., Muller, J. (1992). Literary Encounter and Cultural Studies. From Text to Context. In: Chapman, M., Gardner, C. and Es'kia Mphahlele (eds.) Perspectives on South African English Literature, 475-483. Johannesburg: Ad. Donker.

Wessels, M. (2008). Foraging, Talking and Tricksters. Journal of Folklore Research 45(3): 299-327.

Wessels, M. (2012). The /Xam Narratives of the Bleek and Lloyd Collection. Questions of Period and Genre. Western Folklore 71(1): 25-46.

Wittenberg, H. (2014). The boer and the jackal: satire and resistance in Khoi orature. Critical Arts 28(4): 593-609. 